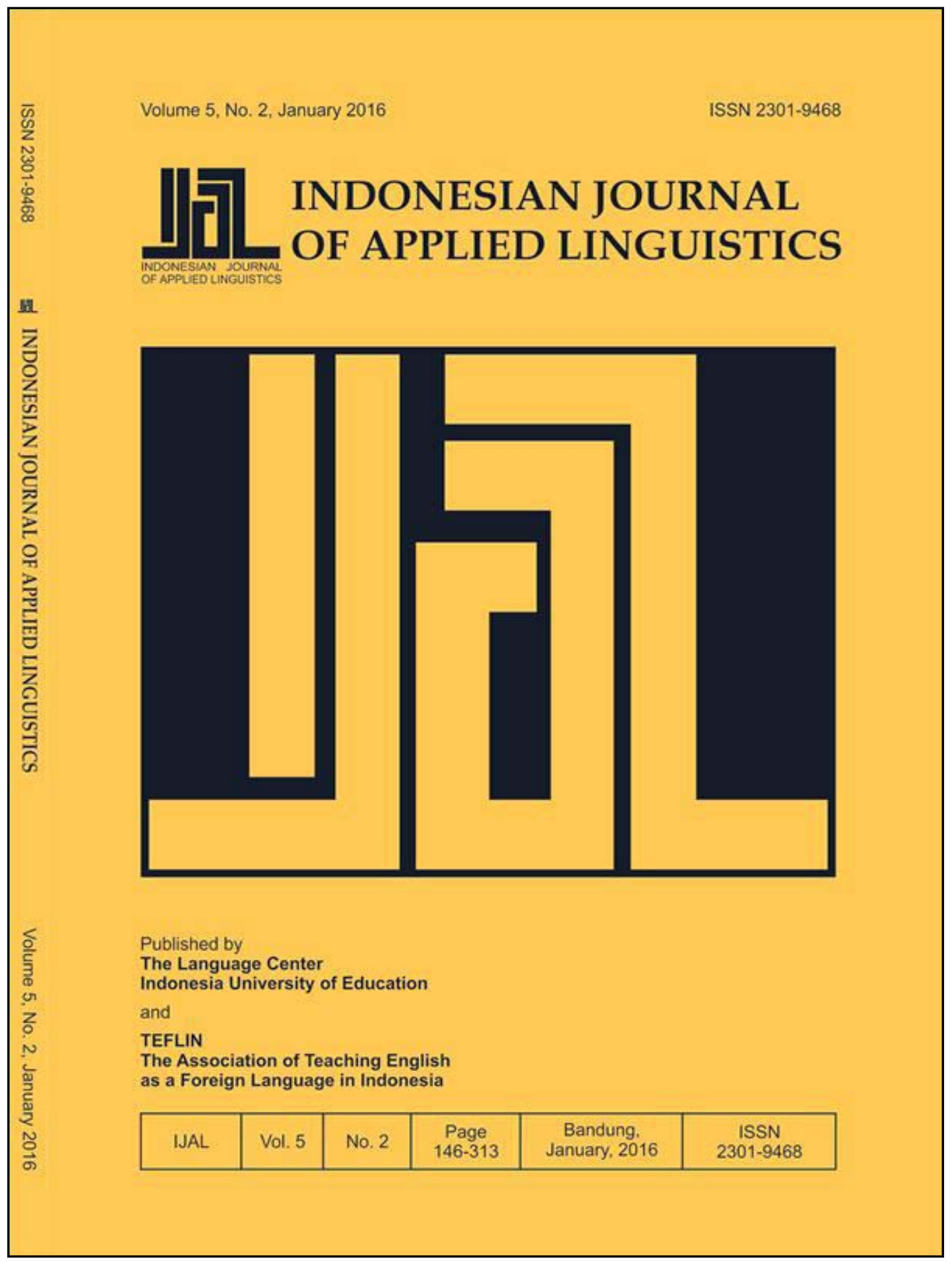

Telah terbit IJAL: International Journal of Applied Linguistic. Jurnal ini diterbitkan setiap bulan Januari, Mei dan September. Jurnal IJAL dikelola oleh para Dosen dari Balai Bahasa UPI (Universitas Pendidikan Indonesia) di Bandung bekerjasama sama dengan Pengurus Pusat TEFLIN (the Association of Teaching English as a Foreign Language in Indonesia); dan diterbitkan oleh UPI Press di Bandung, Jawa Barat, Indonesia. Sejak tahun 2015, jurnal IJAL terindeks oleh lembaga-lembaga pengindeks internasional, seperti SCOPUS, DOAJ (Directory of Open Access Journals), dan Google Scholar. Bagi yang ingin berlangganan dan informasi lebih lanjut, silahkan kunjungi website kami di: www.ejournal.upi.edu; atau hubungi langsung e-mail kami di: dsukyadi@upi.edu 


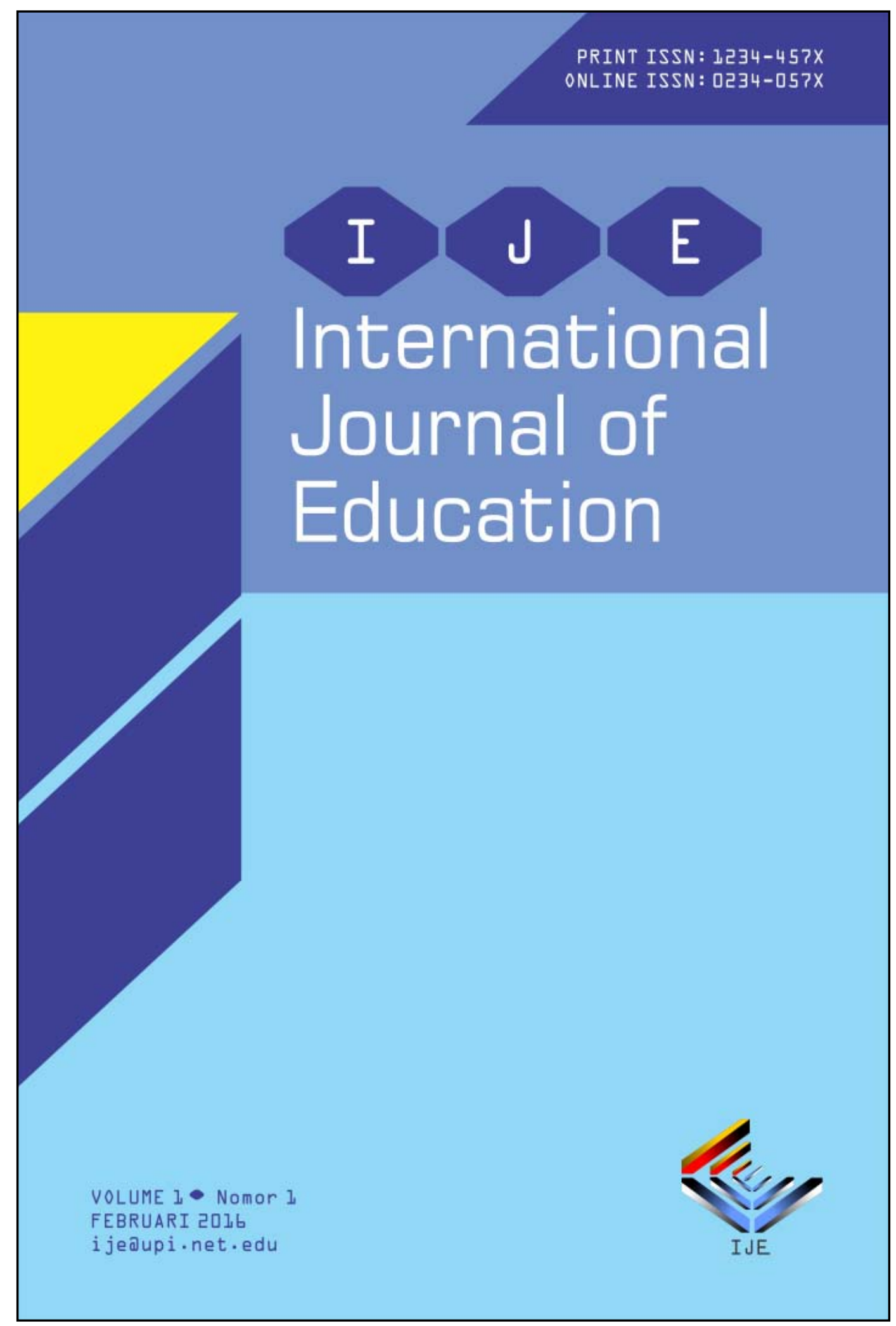

Telah terbit IJE: International Journal of Education. Jurnal ini diterbitkan setiap bulan Februari dan Agustus. Sejak tahun 2016, jurnal IJE dikelola oleh para Dosen dari Timbang (Tim Pengembang) Jurnal UPI (Universitas Pendidikan Indonesia); dan diterbitkan oleh UPI Press di Bandung, Jawa Barat, Indonesia. Bagi yang ingin berlangganan dan informasi lebih lanjut, silahkan kunjungi website kami di: www.ejournal.upi.edu; atau hubungi langsung e-mail kami di: dsukyadi@upi.edu 


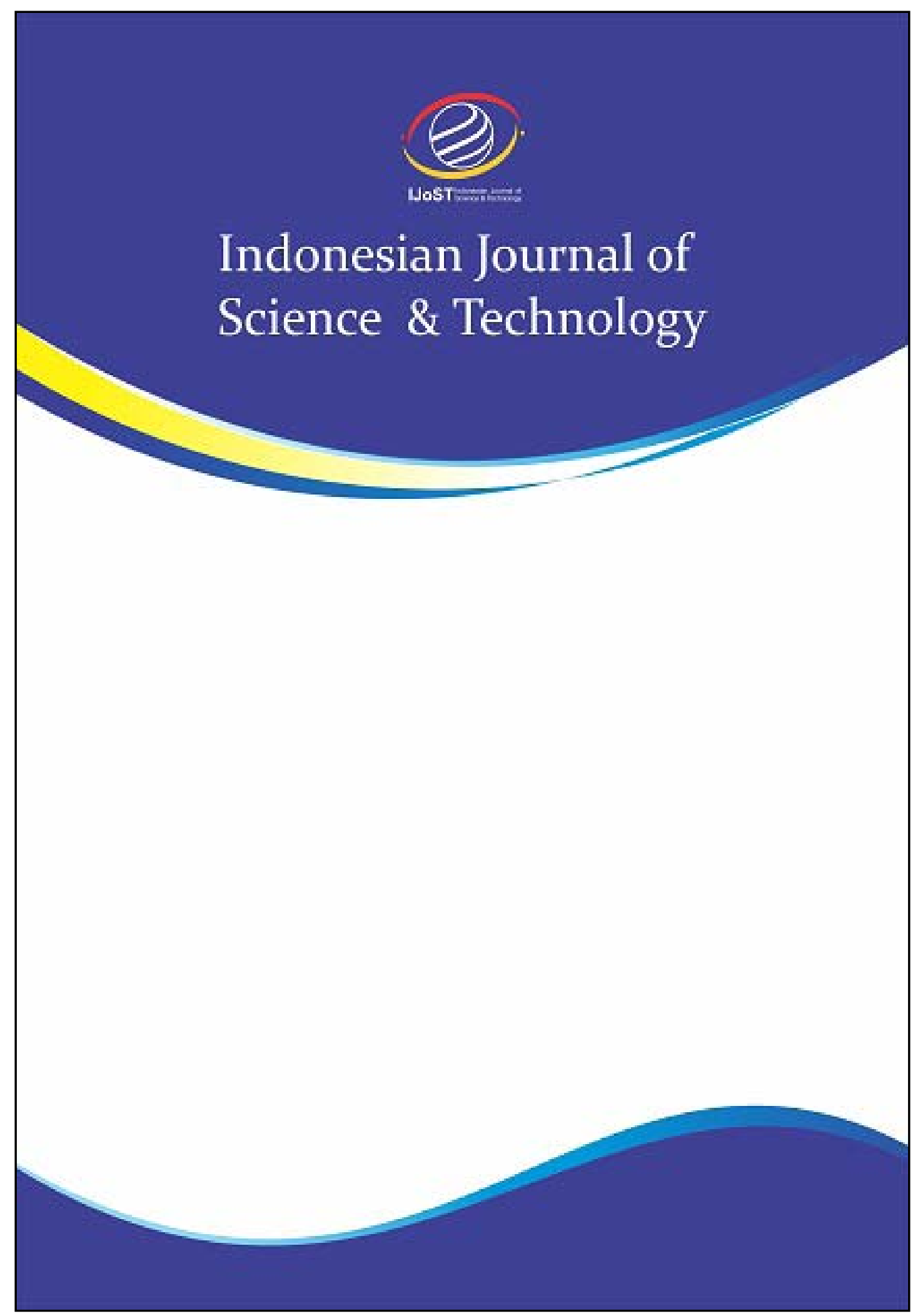

Akan terbit IJoST: International Journal of Science and Technology. Jurnal ini akan diterbitkan setiap bulan April dan Oktober. Sejak pertama kali diterbitkan, pada tahun 2016, jurnal IJoST akan dikelola oleh para Dosen dari Timbang (Tim Pengembang) Jurnal UPI (Universitas Pendidikan Indonesia); dan diterbitkan oleh UPI Press di Bandung, Jawa Barat, Indonesia. Bagi yang ingin berlangganan dan informasi lebih lanjut, silahkan kunjungi website kami di: www.ejournal.upi.edu; atau hubungi langsung e-mail kami di: dsukyadi@upi.edu 


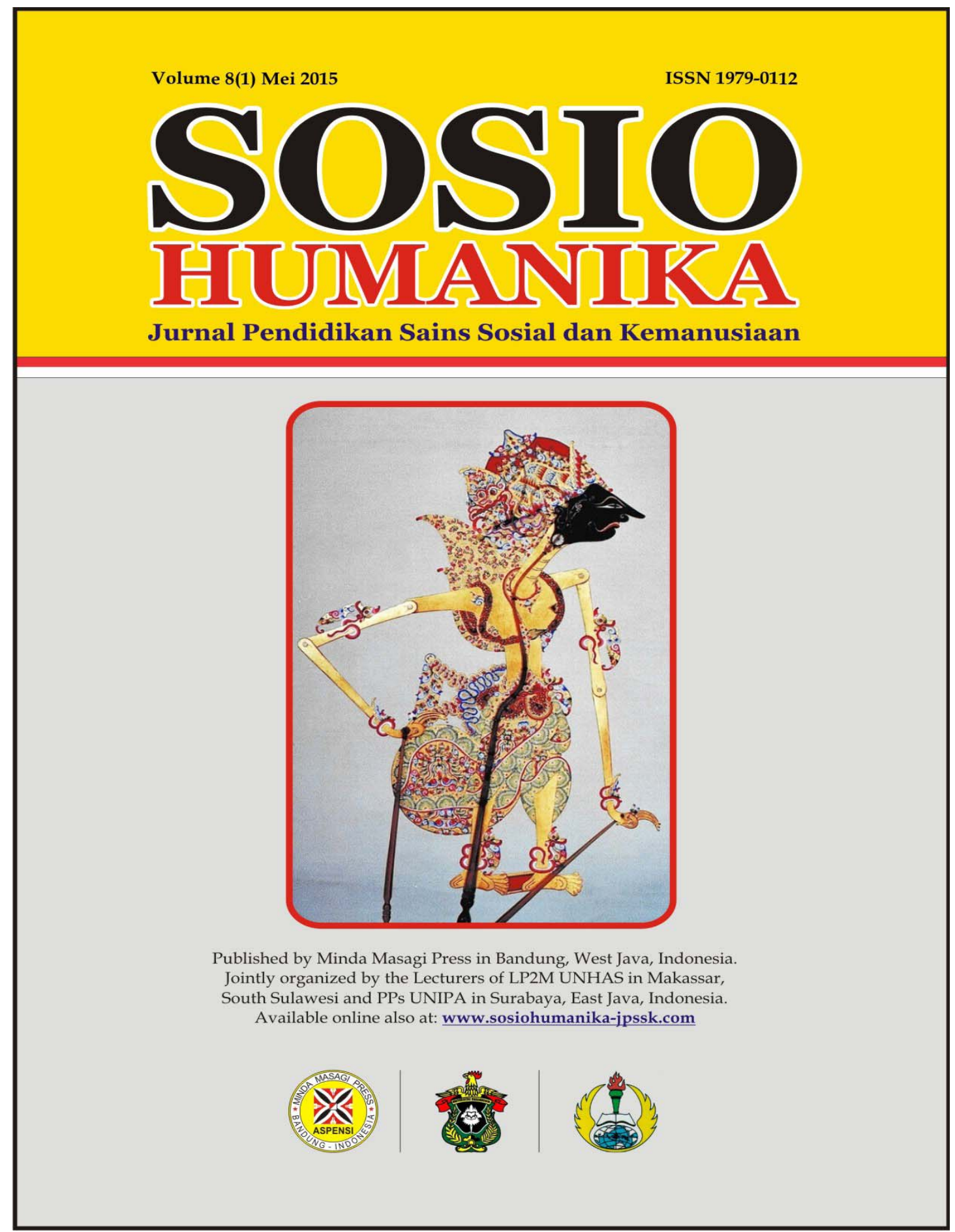

Telah terbit SOSIOHUMANIKA: Jurnal Pendidikan Sains Sosial dan Kemanusiaan. Jurnal ini pertama kali diterbitkan sejak tanggal 20 Mei 2008 dan selalu terbit setiap bulan Mei dan November. Mulai edisi Mei 2016, jurnal SOSIOHUMANIKA akan dikelola oleh para Dosen dari Program Pascasarjana UNIPA (Universitas PGRI Adibuana) di Surabaya, Jawa Timur dan para Dosen dari UPI (Universitas Pendidikan Indonesia) di Bandung, serta diterbitkan bersama oleh Minda Masagi Press sebagai badan penerbitan milik ASPENSI (Asosiasi Sarjana Pendidikan Sejarah Indonesia) dan UPI Press di Bandung, Jawa Barat, Indonesia. Untuk periode 2013-2018, jurnal SOSIOHUMANIKA terakreditasi oleh Ditjendikti Kemdikbud RI (Direktorat Jenderal Pendidikan Tinggi, Kementerian Pendidikan dan Kebudayaan Republik Indonesia). Bagi yang ingin berlangganan dan informasi lebih lanjut, silahkan kunjungi website kami di: www.sosiohumanika-jpssk.com dan www.mindamas-journals.com; atau hubungi langsung e-mail kami di: journal.sosiohumanika@upi.edu dan aspensi@yahoo.com 


\section{INDEX OF AUTHOR}

Abiddin, N.Z. \& A. Ismail. 69-76.

Agyeman, Julian. 2, 10.

Al-Atas, Syed M. Naquib. 26, 28, 36.

Althusser, Louis. 56-57, 67.

Atimono, E. 78, 84.

Ayo, Ruby Ann L. 40-41, 53.

Bammate, Haidar. 26, 36.

Begsma, Lynda. 16, 23.

Belecina, R.R. \& J.M. Ocampo, Jr. 123-136.

Bloom, B.S. 70, 75.

Bowles, Samuel \& Herbert Gintis. 38, 53.

Budiardjo, Mirriam. 56, 67.

Carney, Diana et al. 9-10.

Chickering, A.W. \& L. Reisser. 71, 75.

Clark, Margaret \& Carolyn Page. 40, 53.

Davenport, T.H. \& L. Prusak. 27, 36.

Davis, C.L. \& E. Wilcock. 74-75.

Desy N., Wahyu. 14, 23.

Dionisio, Eleanor R. 44, 53.

Egharevba, J.U. 81, 84.

Eyeh, S.O. 81, 84.

Frankel, A. \& A. Lloyd. 40, 53.

Frederick, P. 73, 75.

Gangel, K.O. 74-75.

Ghosh, S.C. 8, 10 .

Goetz, Anne Marie. 82, 84.

Groeneveldt, W.P. 28-29, 36.

Guerrero, Sylvia H. 38, 53.

Hariyono, Apriliani Hardiyanti. 87-100.

Hey, B. 41-42, 53.

Hitti, Philip K. 28, 36.

Hoare, Q. \& G.N. Smith. 57, 67.

Hu, S. \& G.D. Kuh. 70, 75.

Irabor, F.O. 81, 84

Ismail, A. et al. 70, 75-76.

Kashalkar-Karve, Sanyukta. 6, 10.

Keling, M.F., A.S.P. Mohamed \& M.S. Suhib. 101-122. Wessleyley, L. 38, 54

King, P.M. \& M.M.B. Baxter. 70, 76.

Kostas, Nancy Ann. 51, 53.

Krippendorf, G. 15, 23.

Kurniawan, Mi’raj Dodi \& Andi Suwirta. 55-68.

Laskowski, L. 74, 76.

Levy, P. Yukh. 78, 84.

Lloyd, Christopher. 58, 67.

Lorber, Judith. 38, 53.

Lubis, Nina H. et al. 91, 100.

Osuntokun, J. 79, 85.
Mansur, Kasim. 25-36.

Marwick, Arthur. 58, 68.

Merrill, M.D. 72, 76.

Mingist, Karen. 110, 120.

Moeis, Isnarmi \& Junaidi Indrawadi. 13-24.

Morgen, Sandra. 51, 53.

Mujtaba, S. \& R.M. Lari. 29, 36

Nihardja, Kini. 89, 100.

Noer, Deliar. 56, 68.

Northouse, G. 78, 85.

Nye, Jr., Joseph S. 110, 121.

Olusola, Adesanya Ibiyinka. 77-86.

Othman, Shaharuddin. 107, 121.

Otieno, Dorcas. 9, 10.

Perez, Carina E. 41, 53.

Pitner, S. 72, 76.

Prasad, B. Devi. 15, 23.

Qutub, Sayyed. 26, 36.

Rachmad, Nur. 88, 100.

Rice, Peggy Sue. 51, 53.

Rogers, P.P., J.F. Kazi \& B.A. John. 8, 10.

Sahin, Sagufta \& Jayanta Mete. 1-12.

Sebastian, J. \& E. Allensworth. 74, 76.

Simpson, Bradley R. 102, 121.

Sobritchea, Carolyn I. 41, 54.

Sulasman \& Setia Gumilar. 98, 100.

Suwirta, Andi. 14, 18, 23, 57-59, 68

Sveiby, Karl-Erick. 27, 36.

Tanriverdi, Belgin. 15, 23.

Tantengco, N.S. \& R.L. Maramag. 37-54.

Terwase, Sampson Isaac. 81, 85.

Unal, H. 124, 136.

Venkatanarayanan, S. 8, 11.

Wan, Guafon \& Diane Gut. 14, 23.

Williams, G. Alele. 81, 85.

Williams, R. 74, 76.

Wiriaatmadja, Rochiati. 56-57, 60, 68.

Wood, Michael. 57, 68.

Young, Peter Lewis. 114, 121.

Yunus, Mahmud. 27, 31-32, 36.

Zackry Mokhtar, Mohd. 104, 116, 121.

Zeitchik, S. 78, 85. 


\section{INDEX OF SUBJECT}

Agricultural necessity. 4-5.

Al-Qur'an. 26-28, 31, 35.

Analisis isi pesan nilai. 13-14.

Araling panlipunan. 37-38.

Ateng Japar. 87-88, 92, 96.

Badan Penyelenggara Jaminan Sosial. 18-19.

Basic education reform. 37-38.

Berdikari bukan subsidi. 33-34.

Bergantung kepada pendirian semasa. 108-110.

Biblical model. 77-78.

Cabaran baru ekonomi dunia. 26-27.

Citizenship education. 2-3.

Contemporary Nigeria. 77-78, 82-84.

Dasar pertahanan negara Malaysia. 101-102.

Department of Education. 44-45, 47-51..

District information system for education. 8-9.

Ekonomi Islam sebagai alternatif. 28-31.

Environmental protection. 3-4.

Epistemological beliefs. 12-124, 126.

Esther. 77-79.

Examining gender responsiveness. 37-38.

Fasilitator. 69-70.

Freshman preservice teachers. 123-124.

Gender-fair education. 43-44.

Golongan Karya. 65-66.

Great crisis. 79-80.

Gurukul system. 6-7.

Historiografi buku teks. 55-56.

Human development report. 34-35.

Ideologisasi konsep Reformasi. 55-56.

Institusi pengajian tinggi. 69-70.

Intervention of Esther. 79-80.

Issues. 5-6.

Jakarta. 62-63.

Jawa Barat. 92-93.

K-ekonomi. 27-28.

Kertas putih pertahanan. 106-108.

Knowledge. 4-5.

Konsep Reformasi. 60-67.

Kumpulan kelas. 69-70.

Kurikulum 2013. 14-15.

Leadership. 78-79.

Legenda seni. 87-88.

Livehoods approachs. 8-9.

Longser Pancawarna. 88-89.
Make women's roles. 45-46.

Masalah dalam konsep pertahanan. 115-116.

Matapelajaran pendidikan kewarganegaraa. 13-14.

Mathematical curiosity. 123-124.

Memperkasa ekonomi ummah. 25-26.

Multidisciplinary education. 2-3.

Nigerian women. 80-82.

Nilai tanggungjawab. 18-19.

Non-governmental organization. 9-10.

Old Testament of Adolf Hitler. 80-81.

Organization of Islamic Conference. 35-36.

Pelajaran sejarah di sekolah. 55-56.

Pembangunan modal insan. 31-33.

Perbicangan kumpulan kelas. 69-70.

Pertunjukan longser. 87-88.

Philanthropist. 33-34.

Provide basic human needs. 3-4.

Pusat Latihan Khidmat Negara. 116-117.

Qadrul-hasan. 30-31.

Rezim Orde Baru. 60-61.

Riba'. 28-29.

Roots of ESD in India. 6-7.

Sijil Pelajaran Malaysia. 32-33.

Social studies curriculum. 37-38.

Strategi pembangunan ummah. 25-26.

Struktur self-reliance. 110-112.

Surat kabar Singgalang. 13-14.

Sustainable development. 1-2.

Tatalu. 94-95.

Tentara Nasional Indonesia. 66-67.

Tidak mengambilkira ancaman. 116-118.

Topics for each grade level. 47-48.

United Nations. 3-4.

Upanayana ceremony. 8-9.

Values. 5-6.

Vardha. 6-7.

Violence against women. 45-46.

Wawayangan. 92-93.

Wakil Allah di muka bumi. 29-30.

Women leadership role. 77-78.

Willingness. 7-8.

Yang Berhormat. 108-109.

Zaman Orde Baru. 62-63, 66.

Zona Ekonomi Eksklusif. 102-103. 